\title{
Effect of Some Process Parameters in Enzymatic Dyeing of Wool
}

\section{Tzanko Tzanov, ${ }^{1}$ Carla Joana Silva, ${ }^{1}$ Andrea Zille, ${ }^{1}$ Jovita Oliveira, ${ }^{2}$ and Artur Cavaco-Paulo*,1}

${ }^{1}$ Departamento de Engenharia Têxtil and ${ }^{2}$ Departamento de Polimeros,

Universidade do Minho, Campus de Azurém, 4800-058, Guimarães, Portugal,E-mail: artur@det.uminho.pt

Received December 2002; Revised April 2003; Accepted June 2003

\section{Abstract}

This article reports on the dyeing of wool using an enzymatic system comprising laccase; dye precursor, 2,5-diaminobenzenesulfonic acid; and dye modifiers, catechol and resorcinol. Enzymatic dyeing was performed as a batchwise process at the temperature and $\mathrm{pH}$ of maximum enzyme activity. The effects of the process variables reaction time, enzyme, and modifier concentration on fabric color were studied, according to an appropriate experimental design. Different hues and depths of shades could be achieved by varying the concentration of the modifiers and the time of laccase treatment. The duration of the enzymatic reaction appeared to be the most important factor in the dyeing process. Thus, the dyeing process, performed at low temperature and mild $\mathrm{pH}$, was advantageous in terms of reduced enzyme and chemical dosage.

Index Entries: Enzymatic dyeing; laccase; dye precursors; modifiers; full factorial design.

\section{Introduction}

Laccases (EC 1.10.3.2) are multi-copper oxidases, which catalyze oneelectron oxidation of a wide range of inorganic and organic substances, coupled with one four-electron reduction of oxygen to water $\left(\mathrm{O}_{2}+4 \mathrm{H}^{+}+4 \mathrm{e}\right.$ $\rightarrow 2 \mathrm{H}_{2} \mathrm{O}$ ) (1). Laccases not only catalyze the removal of a hydrogen atom from the hydroxyl group of methoxy-substituted monophenols, ortho- and paradiphenols, butalso can oxidize other substrates such as aromatic amines, syringaldazine, and nonphenolic compounds to form free radicals (2-4).

*Author to whom all correspondence and reprint requests should be addressed. 
Job: ABAB 111/1

Chapter: Tzanov (707-02)

Pub Date: 2003
Operator: $\mathrm{KB}$

Date: $8 / 03$

Revision: 1st galleys

Laccases in both free and immobilized form, as well as from organic solvents, have found various biotechnological and environmental applications, such as removal of toxic compounds from polluted effluents through oxidative enzymatic coupling of the contaminants leading to insoluble complex structures, and as analytical tools-biosensors for phenols (5-11). Laccases have been extensively used in delignification, demethylation, and thereby bleaching of craft pulp $(2,10,12-14)$. The capability of laccases to act on chromophore compounds such as dyes led to the suggestion that they be applied in industrial decolorization processes $(10,15-19)$. Laccases are also known to polymerize phenolic compounds resulting in color generation. The ability of laccases to generate color "in situ" from originally noncolored, low-molecular substances makes their use an alternative to the conventional dyeing processes. In the last few years, various patents reported on coloration achieved with laccase (20-31). Small colorless aromatic compounds such as diamines, aminophenols, aminonaphtols, and phenols, described as dye precursors, are oxidized by laccase to aryloxyradicals. The oxidation of a reducing substrate typically involves formation of a free (cation) radical, which may undergo further nonenzymatic reactions resulting in colored dimeric, oligomeric, and polymeric molecules. At least one of these intermediates in the copolymerization must be an ortho- or paradiamine or aminophenol. Dye precursors can be used alone or in combination with a suitable modifier (coupler)-another phenolic compound-which together with the dye precursor will enlarge the color palette achieved in the enzymatic dyeing. The modifier would react with the dye precursor in the presence of laccase, converting it to a colored compound. Knowledge about the process parameters for the enzyme application, however, is quite limited.

Implementation of biotechnology in the textile industry aims at replacing traditional high chemicals and energy- and water-consuming operations with appropriate enzymatic processes at milder conditions. The objective of the present study was to investigate the dyeing ability of laccases as an alternative to the conventional acid dyes for wool, and to define the optimal experimental conditions to perform the enzymatic dyeing process. Process parameters such as modifier and laccase concentration, and time of dyeing, would influence simultaneously the dyeing result. The classic method of studying one variable at a time may be effective in some situations but fails to consider the combined effects of all the factors involved. Thus, a full factorial design was adopted in order to understand these effects and their interactions.

\section{Materials and Methods}

\section{Enzymatic Dyeing}

The textile material used was scoured $100 \%$ wool fabric. Dyeing was carried out in $0.1 \mathrm{M}$ acetate buffer $(\mathrm{pH} 5.0)$ at $50^{\circ} \mathrm{C}$ with $2.5-10 \mathrm{~mL} / \mathrm{L}$ of

\section{Uncorrected Proof Copy}


Trametes villosa laccase from Novo Nordisk (6.8 g of protein/L), $0.1 \mathrm{M}$ dye precursor (2,5-diaminobenzene sulfonic acid), and 5-50 $\mathrm{mM}$ dye modifiers (catechol or resorcinol), for 1-9 h. All reagents were of analytical grade, provided by Sigma (St. Louis, MO). After dyeing, the fabrics were thoroughly washed at a boil with the nonionic detergent Lutensol ON 30 (BASF) until no more dye was released in the washing bath. A transmission optic microscope (Olympus BH2) with a $\times 40$ magnification was used to observe the dye distribution across the fibers.

\section{Experimental Design}

The influence of the dyeing process variables $(A=$ modifier concentration $[\mathrm{mM}] ; B=$ laccase amount $[\mathrm{mL} / \mathrm{L}] ; C=$ dyeing time $[\mathrm{h}]$ ) on the color of the fabrics was studied using a $2^{3}$ full factorial design with three coded levels leading to 11 sets of experiments. The range and the levels of the independent variables correspond to the ranges of variation of these parameters in the enzymatic recipe for dyeing stated earlier. The data were analyzed using Design Expert software (version 5.0). A second-order polynomial fits the relationships between independent and dependent variables:

$$
\text { (U) } \hat{y}_{i}=\beta_{k 0}+\sum_{i=1}^{3} \beta_{k i} x_{i}+\sum_{i=1}^{3} \beta_{k i i} x_{i}^{2}+\sum_{i=1 ; j=i+1}^{2} \sum_{k i j}^{3} x_{i} \chi_{j}
$$

in which $\hat{y_{i}}$ are predicted responses; $\beta_{k 0^{\prime}} \beta_{k i} \beta_{k i i^{\prime}}$ and $\beta_{k i j}$ are coefficients; and $\chi_{i}$ are the studied codified variables. The responses analyzed were the color characteristics: $K / S, L^{*}, a^{*}, b^{*} . K / S$ is the Kubelka-Munk relationship, in which $K$ is an adsorption coefficient and $S$ is a scattering coefficient. This relationship is applied to textiles under the assumption that light scattering is owing to the fibers, while adsorption of light is owing to the colorant. $L^{*}$, $a^{*}$, and $b^{*}$ are the coordinates of the color in the cylindrical color space, based on the theory that color is perceived by black-white ( $L^{*}=$ lightness), red-green $\left(a^{*}\right)$, and yellow-blue $\left(b^{*}\right)$ sensations. The color of the dyed fabrics was evaluated using a reflectance measuring Datacolor apparatus at standard illuminant $\mathrm{D}_{65}$ (LAV/Spec. Incl., $\mathrm{d} / 8, \mathrm{D}_{65} / 10^{\circ}$ ). Five areas on each sample were measured in various positions, and the results represent average values with up to $1 \%$ variation.

When possible, the model was simplified, eliminating the statistically insignificant terms. Regression and graphic analysis of the experimental data was performed using Design Expert (version 5.0) software. The statistical significance of the regression coefficients and the model equation was determined respectively by student's $t$-test and Fisher test. The proportion of variance explained by the model was given by the multiple coefficient of determination $R^{2}$. The optimum set of variables was obtained by graphic and numerical analysis using the Design Expert program, based on the criterion of desirability. 
Job: ABAB 111/1

Chapter: Tzanov (707-02)

Pub Date: 2003
Operator: $\mathrm{KB}$

Date: $8 / 03$

Revision: 1st galleys

Table 1

Experimental Design and Dyeing Results with Modifiers Catechol and Resorcinol According to $2^{3}$ Factorial Design

\begin{tabular}{|c|c|c|c|c|c|c|c|c|c|c|c|}
\hline \multirow[b]{2}{*}{ Run } & \multicolumn{3}{|c|}{ Variable } & \multicolumn{4}{|c|}{ Catechol response } & \multicolumn{4}{|c|}{ Resorcinol response } \\
\hline & A & B & $\mathrm{C}$ & $K / S$ & $L^{*}$ & $a^{*}$ & $b^{*}$ & $K / S$ & $L^{*}$ & $a^{*}$ & $b^{*}$ \\
\hline 1 & -1 & -1 & -1 & 2.61 & 48.89 & 6.58 & 7.17 & 2.17 & 52.57 & 8.90 & 8.22 \\
\hline 2 & +1 & -1 & -1 & 5.14 & 39.04 & 5.91 & 7.46 & 2.40 & 52.64 & 8.40 & 11.91 \\
\hline 3 & -1 & +1 & -1 & 3.43 & 45.01 & 6.54 & 7.41 & 2.49 & 51.52 & 8.84 & 10.26 \\
\hline 4 & +1 & +1 & -1 & 3.34 & 45.14 & 6.66 & 7.13 & 2.21 & 53.76 & 8.24 & 11.81 \\
\hline 5 & -1 & -1 & +1 & 14.16 & 26.42 & 6.45 & 7.85 & 15.22 & 23.99 & 11.29 & 3.16 \\
\hline 6 & +1 & -1 & +1 & 14.94 & 25.72 & 5.72 & 7.93 & 9.04 & 33.55 & 10.76 & 10.18 \\
\hline 7 & -1 & +1 & +1 & 19.49 & 22.47 & 6.11 & 7.30 & 18.35 & 22.78 & 11.17 & 5.50 \\
\hline 8 & +1 & +1 & +1 & 23.91 & 18.30 & 10.00 & 3.01 & 13.97 & 27.05 & 10.65 & 8.05 \\
\hline 9 & 0 & 0 & 0 & 11.50 & 28.72 & 6.31 & 7.56 & 7.95 & 33.75 & 10.04 & 7.25 \\
\hline 10 & 0 & 0 & 0 & 12.86 & 27.24 & 6.17 & 7.42 & 8.89 & 32.47 & 10.29 & 7.49 \\
\hline 11 & 0 & 0 & 0 & 14.36 & 25.77 & 6.10 & 7.16 & 9.60 & 31.11 & 10.01 & 6.80 \\
\hline
\end{tabular}

\section{Results and Discussion}

Screening experiments were conducted to identify which process parameters influence the color (in terms of $K / S, L^{*}, a^{*}$, and $b^{*}$ ) of the enzymatically dyed fabrics. The effects of different experimental variables on the dyeing results were simultaneously inyestigated, applying a full factorial design experiment. The experimental matrix and the results are presented in Table 1.

The first step in the process of seeking optimal conditions for the enzymatic dyeing is to identify the input variables with greatest influence on the responses. $K / S$ and lightness values of the dyed fabrics at the dye absorption maximum varied considerably (Table 1 ). The function $K / S$ is directly proportional to the concentration of the colorant on the substrate and indicates the dye adsorption and fixation. In our dyeing experiments, $K / S$ reflected the amount of fixed dye, since all the unfixed dyestuff was presumably washed off. For the modifier catechol, $K / S$ varied from 2.61 to 23.91 and $L^{*}$ from 48.89 to 18.30 . For the other modifier, $K / S$ values ranged from 2.17 to 18.35 and $L^{*}$ from 53.76 to 22.78 . The highest $K / S$ value for catechol was achieved at the uppermost levels of the three factors. Interestingly, for resorcinol the highest $K / S$ value was attained when the modifier was applied at the lowest concentration, while the amount of enzyme and the time of treatment were at their highest levels. Catechol and resorcinol are, respectively, ortho- and metasubstituted diphenols. Considering runs 7 and 8 , the fabrics dyed with catechol appeared redder and bluer with the increase in modifier concentration, while the samples dyed with resorcinol became yellower and greener. Obviously the position of the second $\mathrm{OH}$ group in the molecule of the modifier was responsible for the different coloration behavior and the change in hue. This could be explained by the 


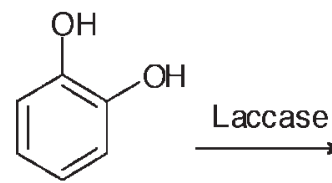<smiles>O=C1C=CC=CC1=O</smiles>

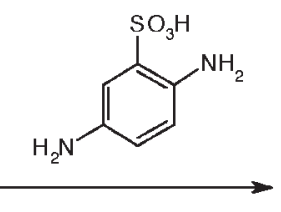<smiles>Nc1ccc(Nc2ccc(O)c(O)c2)cc1S(=O)(=O)O</smiles>

Scheme 1. Expected mechanism of reaction between dye precursor and modifier.

different pathway of the enzymatically catalyzed reaction between the dye precursor and modifier. Laccase oxidizes the phenolic compounds, converting them to reactive quinone species, which subsequently react nonenzymatically with amines forming 1,4-Michael-type adducts (Scheme 1). The orthosubstituted diphenol-catechol can further undergo another Michael's addition of amine and develops deeper than that of the resorcinol color (Table 1). The orthodiphenols were reported as better substrates for laccase than the metasubstitutes (32). Apart from reacting with the dye precursor, the phenol modifiers could undergo an oxidatively induced polymerization. Thus, the laccase-mediated oxidation of the dye precursor and modifiers results in highly reactive radicals, which can undergo either self- or cross-propagation with the respective monomers in a way very complex for characterization.

Independently of the other variables, increasing the dyeing time from 1 to $9 \mathrm{~h}$ (dyeing temperature of $50^{\circ} \mathrm{C}, \mathrm{pH} 5.0$ ) drastically increased $\mathrm{K} / \mathrm{S}$ and decreased $L^{*}$ values. By comparison, the duration of the conventional chemical dyeing process is normally 3 to $4 \mathrm{~h}$, at boiling temperature in highly acidic medium. Problems have been experienced with all attempts to introduce low-temperature methods for wool dyeing, necessitating application of various auxiliaries or solvents to effect diffusion of the dye into the fibers, and even then the temperatures were in the range of 60 $80^{\circ} \mathrm{C}$. This high time-dependent increase in $\mathrm{K} / \mathrm{S}$ suggested that a deeper color could be achieved simply by prolonging the contact time between the textile material, enzyme, dye precursor, and modifier, in contrast to the conventional dyeing of wool, in which the depth of the color is proportional to the amount of dye. It is not clear, however, whether the dye was formed in the solution and then was adsorbed on the textile material, or whether it was formed directly on the fabric. Both possibilities exist, since the reactive colored compounds adsorbed on the fabric could continue to interact nonenzymatically. The presence of sulpho-groups in the molecule of the dye precursor provides both solubility of the dye and substantivity toward the wool material. The increase in $K / S$ also indicated a higher dye presence on the fabric. The cross-section image of the enzymatically dyed fibers in 


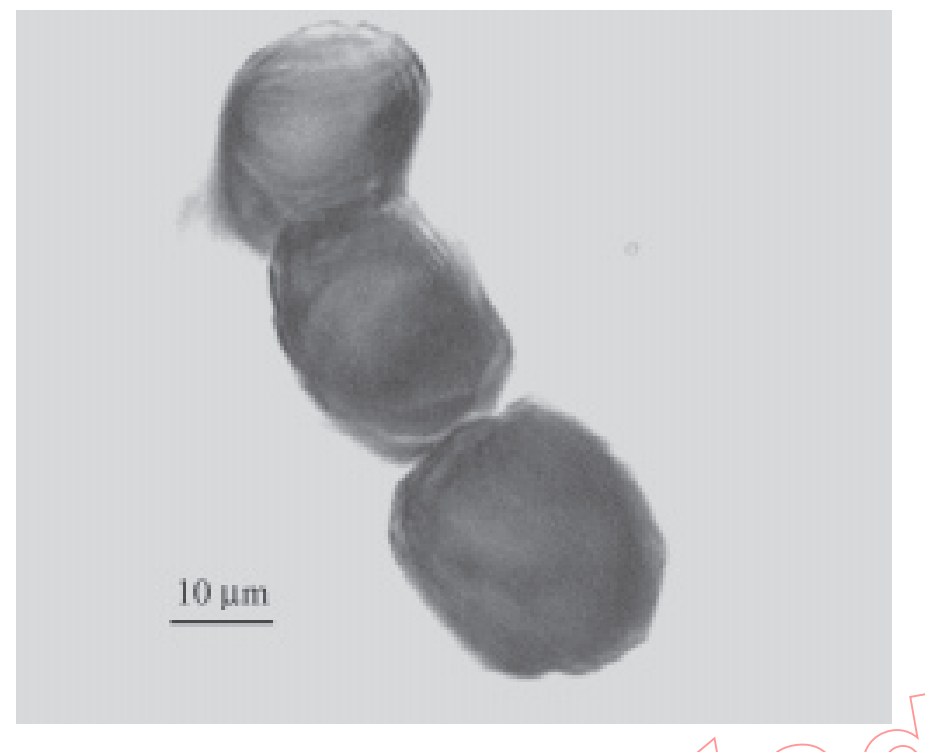

Fig. 1. Microscopic photograph of cross-section of wool fibers (original magnification: $\times 40$ ) dyed according to trial 8 from the adopted full factorial design (with catechol).

Fig. 1 shows penetration of the dye into the interior of the keratin fiber. This image suggests that the small molecules of the dye precursor and modifiers could penetrate beyond the wool cuticles and some portion of the color was formed in the fiber itself. The small size of the dyeing molecules provides levelness of the dyeing.

Statistical analysis for each of the response variables according to the student's $t$-test (Table 2) showed that the factor with the most significant effect (99\% confidence level in most cases) on all responses was the time of dyeing.

\section{Analysis of Modifier Catechol}

Models for responses $a^{*}$ and $b^{*}$ were not derived, since the plots of the normal distribution of the residues showed a nonaleatory distribution. All the factors and their interactions were very significant and no residues were left for the error analysis. Although the color can be split into three components $-L^{*}, a^{*}$, and $b^{*}$-only the first is immediately meaningful in practice since the sign of $L^{*}$ sample $-L^{*}$ standard indicates that the sample is lighter if $\Delta L^{*}$ is positive and darker if negative. The model expressed by Eq. 2 represents $K / S\left(y_{1}\right)$ as a function of laccase amount $(B)$ and dyeing time $(C)$ :

$$
\hat{y}_{1}=10.88+1.67 \times B+7.25 \times C+1.91 \times B C
$$

This linear model was evaluated as statistically significant $(p<0.0001)$ at a $99 \%$ confidence level by $F$-test (analysis of variance [ANOVA]). The model did not show lack of fit and presented a high determination coefficient $\left(R^{2}=0.96\right)$, explaining $96.5 \%$ of the variability in the response.

\section{Uncorrected Proof Copy}


Job: ABAB 111/1

Chapter: Tzanov (707-02)

Pub Date: 2003
Operator: $\mathrm{KB}$

Date: $8 / 03$

Revision: 1st galleys

Enzymatic Dyeing of Wool

Table 2

Estimated Effects, Standard Errors, and Student's $t$-Test for Most Important Output Parameters

with Modifier Catechol and Resorcinol According to $2^{3}$ Full Factorial Design

\begin{tabular}{|c|c|c|c|c|c|c|c|c|}
\hline \multirow[b]{3}{*}{ Factor } & \multicolumn{4}{|c|}{ Catechol } & \multicolumn{4}{|c|}{ Resorcinol } \\
\hline & \multicolumn{2}{|c|}{$K / S( \pm 0.51)$} & \multicolumn{2}{|c|}{$L^{*}( \pm 0.52)$} & \multicolumn{2}{|c|}{$K / S( \pm 0.29)$} & \multicolumn{2}{|c|}{$L^{*}( \pm 0.47)$} \\
\hline & Effect & $t$ Value & Effect & $t$ Value & Effect & $t$ Value & Effect & $t$ Value \\
\hline Mean & 10.88 & - & 33.87 & - & 8.23 & - & 39.73 & - \\
\hline$A$ & 0.96 & 1.89 & -1.82 & $-3.50 *$ & -1.33 & $-4.53^{\ddagger}$ & 2.02 & $4.32^{\ddagger}$ \\
\hline B & 1.66 & $3.29^{*}$ & -1.14 & -2.19 & 1.02 & $3.50^{*}$ & -0.96 & -2.05 \\
\hline$C$ & 7.25 & $14.33^{+}$ & -10.65 & $-20.41^{\dagger}$ & 5.91 & $20.21^{+}$ & -12.89 & $-27.62^{+}$ \\
\hline$A B$ & 0.13 & 0.25 & 0.81 & 1.56 & 0.16 & 0.55 & -0.39 & -0.84 \\
\hline$A C$ & 0.34 & 0.68 & 0.61 & 1.16 & -1.31 & $-4.49^{\ddagger}$ & 1.44 & $3.09^{*}$ \\
\hline$B C$ & 1.91 & $3.78^{*}$ & -1.70 & $-3.26^{*}$ & 0.99 & $3.39 *$ & -0.97 & -2.08 \\
\hline$A B C$ & 0.78 & 1.55 & -1.68 & $-3.22^{*}$ & 0.29 & 0.99 & -0.93 & -2.00 \\
\hline
\end{tabular}

${ }^{*} p<0.10 ;{ }^{+} p<0.01 ;{ }^{\ddagger} p<0.05$.

The response contours described by the model equation $\left(y_{1}\right)$ showed that a maximum $K / S$ value can be obtained by carrying out the dyeing with $10 \mathrm{~mL} / \mathrm{L}$ of laccase, for $9 \mathrm{~h}$ (Fig. 2). Interestingly, for the first hours of dyeing, observing the surface contour for $K / S$, the relation between the time of reaction and the laccase concentration was almost a straight line. This means that further addition of enzyme to the dye bath would not alter the depth of color. However, with the increase in dyeing time these two factors begin to interact and $K / S$ tends to increase as well.

For the lightness values $\left(L^{*}\right)$, the time factor and the modifier concentration were revealed to be significant with a confidence level of 99.8 and $92.7 \%$, respectively. Thus, these two factors and their interactions were included in the model (Eq. 3) estimating the lightness as a function of time and modifier concentration.

$$
\hat{y}_{2}=33.87-1.82 \times A-10.65 \times C+0.61 \times A C
$$

ANOVA for the model showed that the regression was statistically significant $(p=0.0006)$ at a $1 \%$ probability level and also presents a good determination coefficient $\left(R^{2}=0.93\right)$, without lack of fit.

Considering the response surface of the lightness over the independent variables modifier concentration and time (Fig. 3), low lightness values (i.e., darker color) were attained at longer dyeing time. However, there is a compromise between time and modifier concentration, in a way that it is possible to reduce the modifier dosage and to reach the same lightness values by increasing the process time.

Based on the two models, a graphic optimization was performed using the Design Expert program. The method consists of overlaying the curves of all the models according to the criteria imposed. The optimal working 
Job: ABAB 111/1

Chapter: Tzanov (707-02)

Pub Date: 2003
Operator: $\mathrm{KB}$

Date: $8 / 03$

Revision: 1st galleys

8

Tzanov et al.

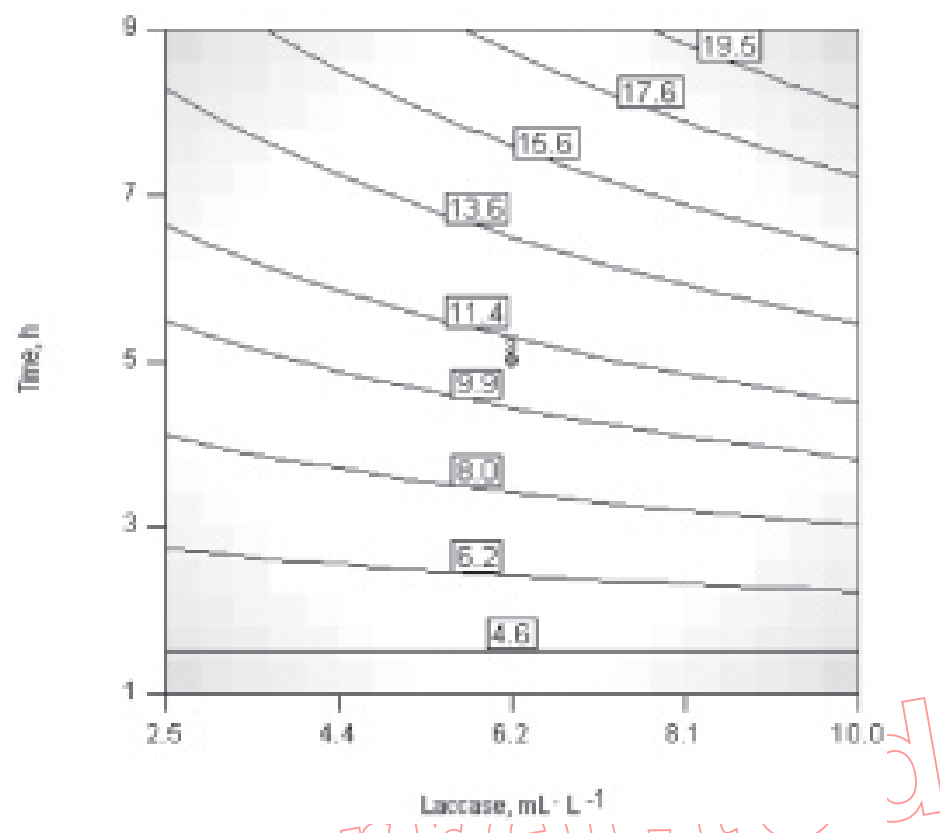

Fig. 2. Contour plot of $K / S$ as function of laccase concentration and reaction time. The factor modifier was kept constant (27.5 $\mathrm{mM}$ catechol).

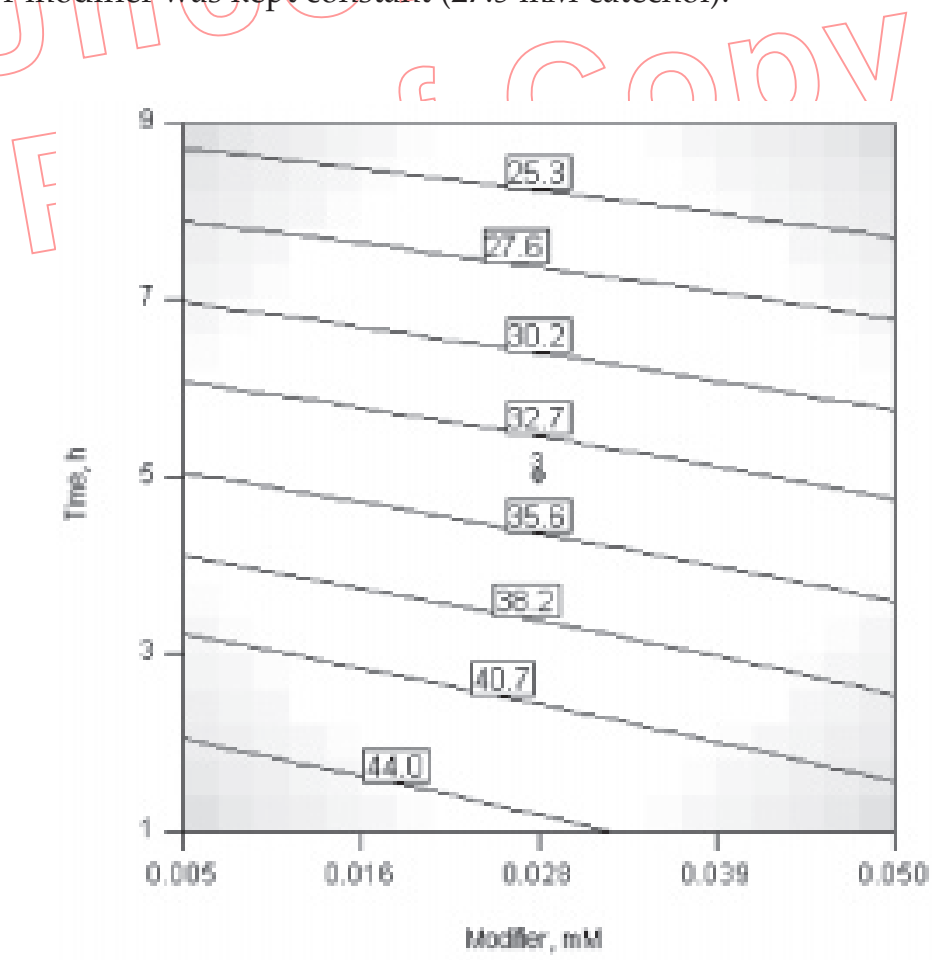

Fig. 3. Contour plot of $L^{*}$ as function of modifier (catechol) concentration and reaction time. The factor laccase was kept constant $(6.2 \mathrm{~mL} / \mathrm{L})$. 


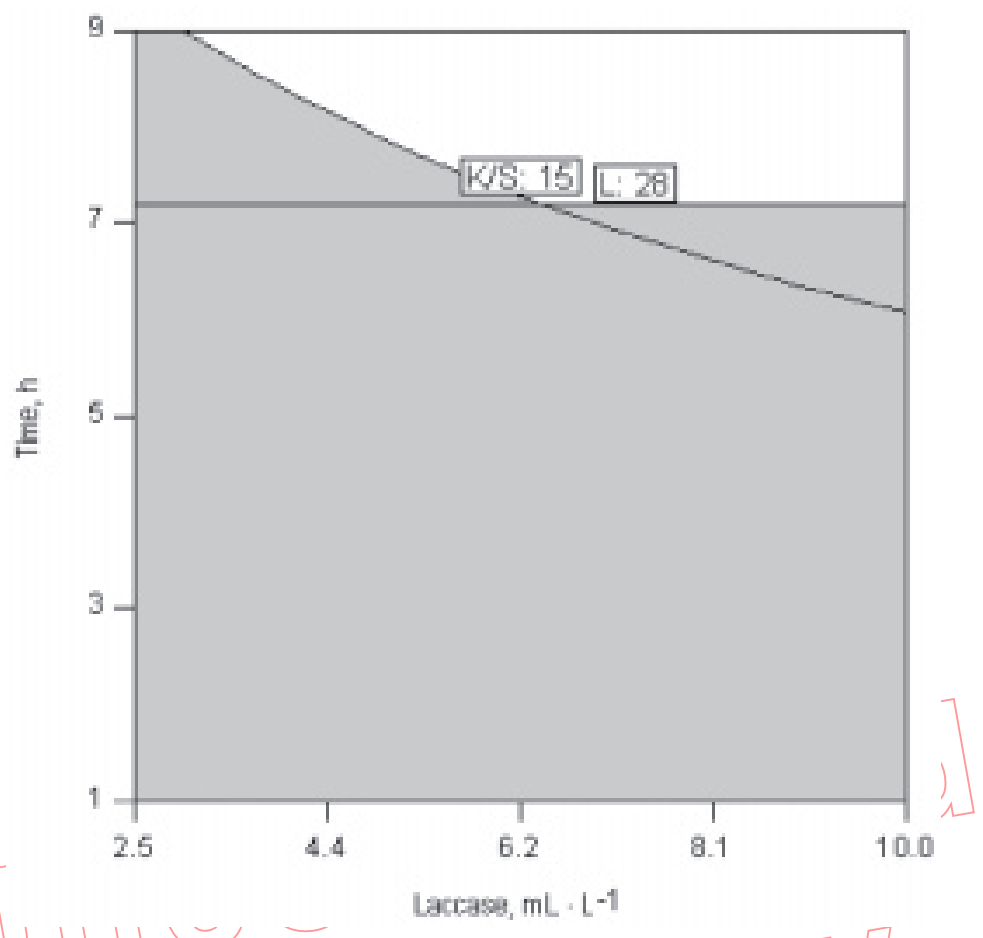

Fig. 4. Optimum region defined by overlaid plots of two responses $K / S$ and $L^{*}$ evaluated for modifier catechol as function of laccase concentration and reaction time. The modifier was kept constant $(27.5 \mathrm{mM})$.

conditions were defined so that high $K / S$ and low lightness values were obtained. The criteria adopted were a $K / S>15$ and lightness value inferior to 28. The nonshaded area in the overlaying plot in Fig. 4 corresponds to the levels of the process variable where all the criteria imposed were satisfied.

\section{Analysis of Modifier Resorcinol}

The model representing $K / S()$ as a function of modifier $(A)$ and laccase $(B)$ concentration, and dyeing time $(C)$ was expressed by Eq. 4:

$$
\hat{y}_{3}=8.23-1.33 \times A+1.02 \times B+5.91 \times C-1.31 \times A C+0.99 \times B C
$$

The F-test (ANOVA) revealed the statistical significance of the regression $(p=0.0002)$ at a $99.9 \%$ confidence level. The model did not show lack of fit and exhibited a high determination coefficient $\left(R^{2}=0.99\right)$, explaining $99.3 \%$ of the variability in the response. The model did not present curvature, and the interactions $A B$ and $A B C$ were removed from the equation, since they were not significant at the $90 \%$ confidence level.

The response contours described by the model equation $\left(\hat{y}_{3}\right)$ are presented in Fig. 5. Maximum $K / S$ on dyed fabrics would be obtained by applying $10 \mathrm{~mL} / \mathrm{L}$ of laccase, for $9 \mathrm{~h}$ of treatment, using the modifier in its lowest concentration. Analysis of the two contours presented in Fig. 5 
Job: ABAB 111/1

Chapter: Tzanov (707-02)

Pub Date: 2003

10

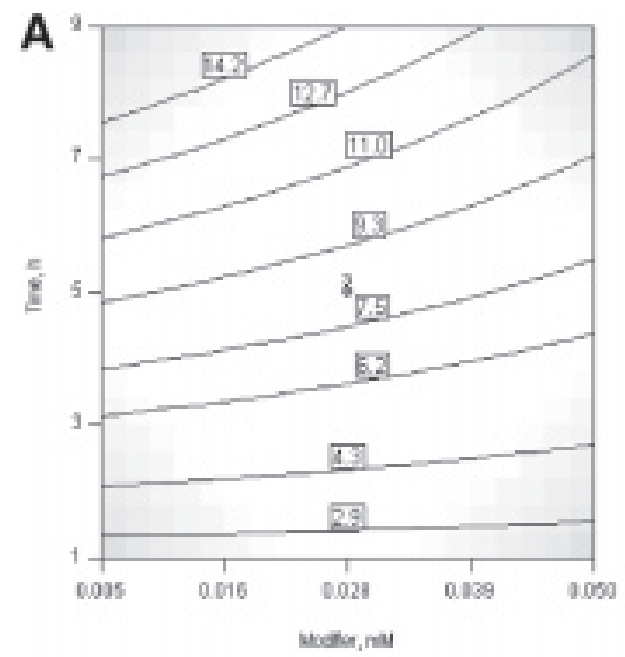

Operator: $\mathrm{KB}$

Date: $8 / 03$

Revision: 1st galleys

Tzanov et al.

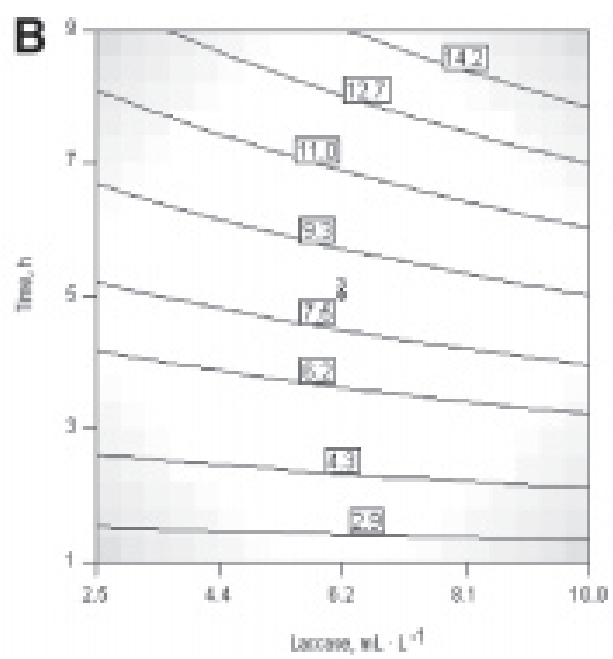

Fig. 5. Contour plots of $K / S$ as function of modifier resorcinol (A) or laccase (B) concentration and time of reaction. The other factor was kept at the zero level.

reveals that the same values of $K / S$ (i.e., depth of color on fabrics) could be attained at constant reaction time, by increasing the enzyme and decreasing the modifier concentration. For a short duration of the process, the relation between the factors is linear, which implies that only time is really significant in this region of study. When the time of dyeing was increased, the other two factors started to reveal an interaction effect.

For the lightness of the dyed fabrics only the modifier concentration $(A)$, time of dyeing $(C)$, and their interactions were statistically significant at a $90 \%$ confidence level. The mathematical model representing the lightness factor $\left(y_{4}\right)$ in the experimental region studied was as follows:

$$
\hat{y}_{4}=39.73+2.02 \times A-12.89 \times C+1.44 \times A C
$$

The regression was statistically significant ( $<99.99 \%$ confidence level) and presented a good determination coefficient, explaining $98 \%$ of the total variation in the response, the remaining $2 \%$ being explained by the residues.

The response contours of the lightness factor $\left(y_{4}\right)$ over the independent variables (Fig. 6) showed that the lightness was minimum (which implies darkest color) when the time of dyeing was at its maximum and the modifier concentration was at the minimum level.

Based on the two models obtained for this modifier, a graphic optimization was conducted using the Design Expert program. The optimal working conditions were defined to perform dyeing of the textile material in a deep shade, i.e., high $K / S$ and low lightness values. The criteria adopted were a reflectance value $>10$ and a lightness value inferior to 35 . The overlaying plot in Fig. 7 shows a nonshaded area where both the criteria imposed were satisfied. Optimization was carried out regarding the concentration of laccase, the most costly component in the dyeing mixture. 
Job: ABAB 111/1

Chapter: Tzanov (707-02)

Pub Date: 2003
Operator: $\mathrm{KB}$

Date: $8 / 03$

Revision: 1st galleys

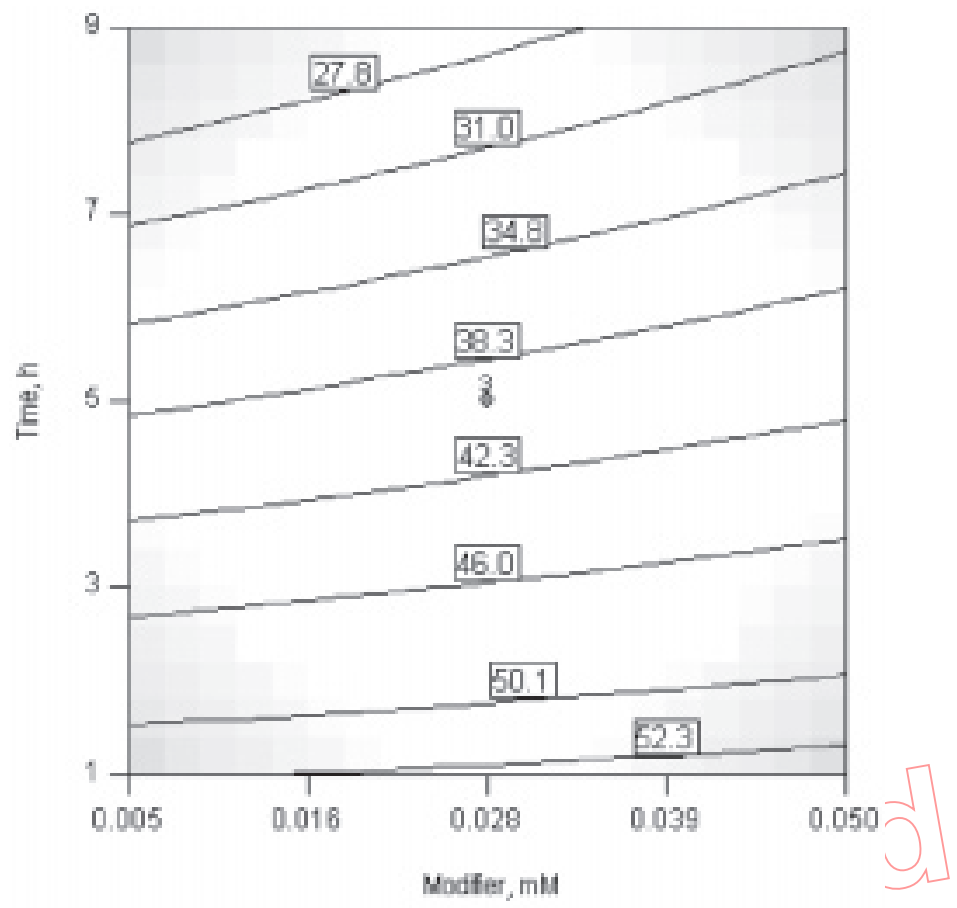

Fig. 6. Contour plot of $L^{*}$ as function of modifier (resorcinol) concentration and reaction time. The factorlaccase was kept constant $(6.2 \mathrm{~mL} / \mathrm{L})$.

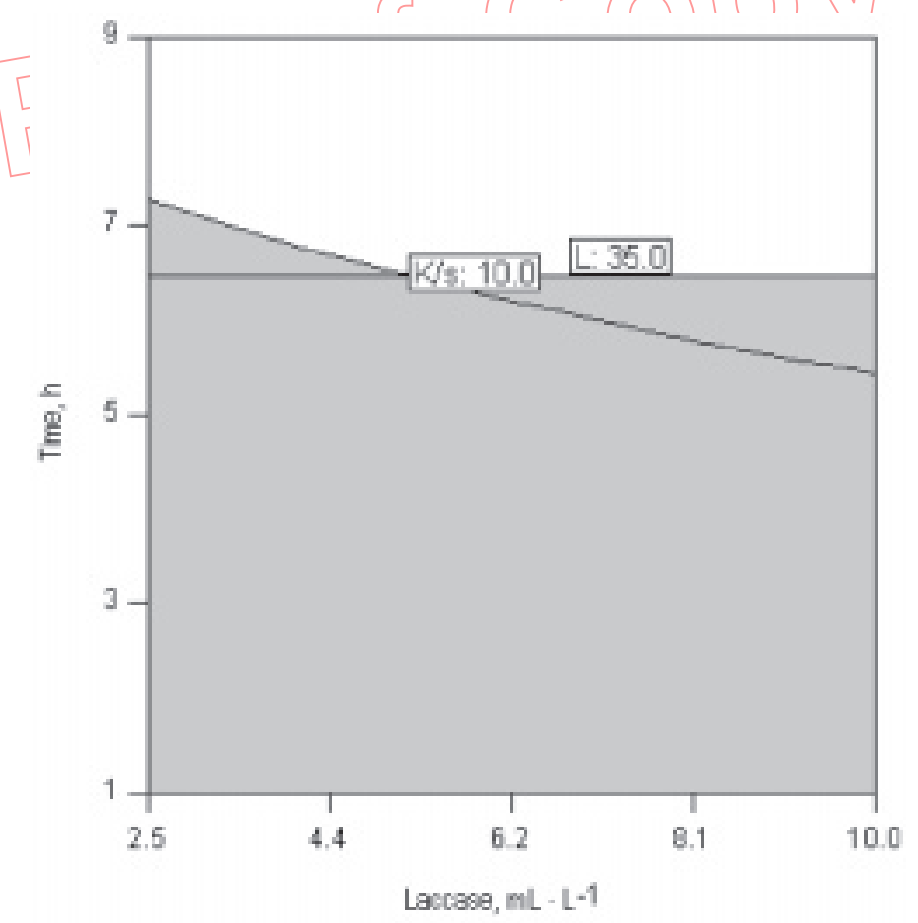

Fig. 7. Optimum region defined by overlaid plots of two responses $K / S$ and $L^{*}$ evaluated for modifier resorcinol as function of laccase concentration and reaction time. The other factor was kept at the zero level. 


\section{Conclusion}

This study was an attempt to optimize the process variables of a novel laccase-assisted dyeing process of wool. Dyeing was performed in a dye bath prepared with a dye precursor (2,5-diaminobenzenesulfonic acid) and dye modifiers (catechol and resorcinol) and laccase, without any dyeing auxiliaries. Increasing the reaction time and minimizing the enzyme and modifiers loading could obtain darker coloration of the samples. This renders the laccase dyeing an economically attractive alternative to the conventional use of high-water, dyes, auxiliaries, and energy-consuming acid to dye wool. Additionally, the enzymatic reaction was carried out at a $\mathrm{pH}$ and temperature safe to the textile material. The dyeing experiments with two modifiers having the same molecular weight but with different position of the substitutes revealed the potential of the enzymatic approach for achieving a large diversity of colors and hues on the fabrics, varying the starting compounds. Comparison of the two modifiers showed that the concentration was not statistically significant for the color depth in the case of catechol, but very significant in the case of resorcinol. Statistical analysis showed that resorcinol should be used in tow concentration to attain deepshade dyeing. Microscopic observation of the cross-section of the enzymatically dyed wool demonstrated penetration of the colorant into the mass of the fibers.

\section{Acknowledgments}

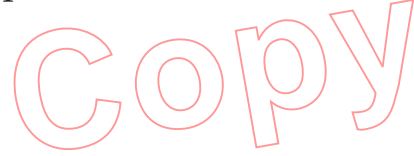

We acknowledge the HPMF-CT-2000-00868 project for providing a grant to Dr. Tzanov, as well as the Fundação para a Ciência e Tecnologia (Portugal), through PhD fellowships to C.J.S. (PRAXIS XXI SFRH/BD/ 1292/2000) and to A.Z. (PRAXIS XXI SFRH/BD/4720/2001).

\section{References}

1. Xu, F. (1996), Biotechnology 85, 7608.

$>$ Au:

Patents correct throughout? Add commas to numbers?
2. Li, K., Xu, F., and Eriksson, K. (1999), Appl. Environ. Microbiol. 65, 2654.

3. Chen, C. L., Gratzl, J. S., Kirkman, A. G., Potthast, A., and Rosenau T. (1999), North Carolina State University, Patent US5888787.

4. Robles, A., Lucas, R., de Cienfuegos, A. G., and Galvez, A. (2000), Enzyme Microb. Technol. 26, 484.

5. Gardiol, A., Hernandez, R., Reinhammar, B., and Harte, B. R. (1996), Enzyme Microb. Technol. 18, 347.

6. Ghindilis, A., Makower, A., Bauer, C., Bier, F., and Scheller, F. (1995), Anal. Chim. Acta 304, 25.

7. Hublik, G. and Schinner, F. (2000), Enzyme Microb. Technol. 27, 330.

8. Lante, A., Crapisi, A., Krastanov, A., and Spettoli, P. (2000), Process Biochem. 36, 51.

9. Xu, F. (1996), Biochemistry 35, 7608.

10. Schneider, P. and Pedersen, A. H. (1998), Novo Nordisk A/S, Patent US5795855.

11. Hopkins, T. R. (1984), Phillips Petroleum Company, Patent US4485016.

12. Bourbonnais, R. and Paice, M. (1992), Appl. Microbiol. Biotechnol. 36, 823.

13. Bourbonnais, R., Paice, M., Freiermuth, B., Bodie, E., and Borneman, S. (1997), Appl. Environ. Microbiol. 63, 4627.
$<$ Au: Pls. provide inclusive page numbers throughout.

\section{Uncorrected Proof Copy}


Job: ABAB 111/1

Chapter: Tzanov (707-02)

Pub Date: 2003
Operator: $\mathrm{KB}$

Date: $8 / 03$

Revision: 1st galleys

Enzymatic Dyeing of Wool

14. Bourbonnais, R., Paice, M., Reid, I., Lanthier, P., and Yaguchi, M. (1995), Appl. Environ. Microbiol. 61, 1876.

15. Abadula, E., Tzanov, T., Costa, S., Robra, K. H., Cavaco-Paulo, A., and Gubitz, G. (2000), Appl. Environ. Microbiol. 66, 3357.

16. Morita, M., Ito, R., Kamidate, T., and Watanabe, H. (1996), Textile Res. J. 66, 470.

17. Damsus, T., Kirk, O., Pedersen, G., and Venegas, M. G. (1991), Novo Nordisk A/S, The Procter \& Gamble Company, Patent WO9105839.

18. Pedersen, G. and Schmidt, M. (1992), Novo Nordisk A/S, Patent WO9218687.

19. Pedersen, A. H. and Kierulff, J. V. (1996), Novo Nordisk A/S, Patent WO9612845.

20. Sørensen, N. H. (1999), Novo Nordisk A/S, Patent CA2303125.

21. Aaslyng, D., Sørensen, N. H., and Rørbæk, K. (1999), Novo Nordisk A/S, Patent US5948121.

22. Aaslyng, D., Sørensen, N. H., and Rørbæk, K. (1999), Novo Nordisk A/S, Patent AU706338.

23. Sørensen, N. H. (1999), Novo Nordisk A/S, Patent WO9915137.

24. Rørbæk, K., Aaslyng, D., and Sørensen, N. H. (1998), Novo Nordisk A/S, Patent CN1203615.

25. Rørbæk, K., Aaslyng, D., and Sørensen, N. H. (1997), Novo Nordisk A/S, Patent CA2238697.

26. Rørbæk, K., Aaslyng, D., and Sørensen, N. H. (1998), Novo Nordisk A/S, Patent EP0865465.

27. Rørbæk, K., Aaslyng, D., and Sørensen, N. H. (1997), Novo Nordisk A/S, Patent AU7622096.

28. Aaslyng, D., Rørbæk, K., and Sørensen, N.H. (1997), Novo Nordisk A/S, Patent W09719999.

29. Martin, R., Jumino, A., Dubief, C., Rosenbaum, G., and Audousset, M. P. (1994), Oreal, FR2694018.

30. Barfoed, M., Kirk, O., and Salmonm,S. (2001), Novozymes A/S, Patent US2001037532.

31. Shin, H., Guebitz, G., and Cavaco-Paulo, A. (2001), Macromol. Mater. Eng. 286, 691.

32. Thurston, C. F. (1994), Microbiology 140, 19. 
Job: ABAB 111/1

Chapter: Tzanov (707-02)

Pub Date: 2003
Operator: KB

Date: $8 / 03$

Revision: 1st galleys

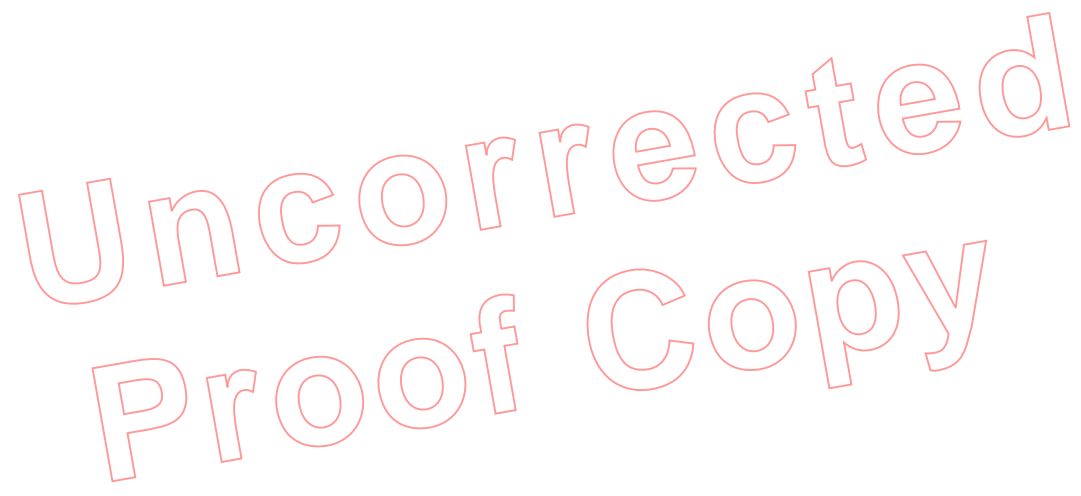

